\title{
Research on Port Integration and Sustainable Development in the Guangdong-Hong Kong-Macao Greater Bay Area
}

\author{
Xuan-Fei WANG ${ }^{1, a}$, Zhong-Hao LIN $^{2, b}$ and Shan LIANG ${ }^{3, c, *}$ \\ ${ }^{1}$ School of Information, Guangdong University of Finance and Economics, Guangzhou, 510320, \\ China \\ ${ }^{2}$ Guangdong-Hong Kong-Macao Greater Bay Area Research Center, Guangdong University of \\ Finance and Economics, Foshan, 528100, China \\ ${ }^{3}$ Guangzhou College of South China University of Technology, Guangzhou, 510800, China

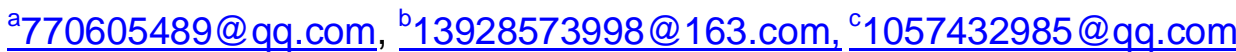

\begin{abstract}
Keywords: Guangdong-Hong Kong-Macao Greater Bay Area, port integration, sustainable development, game theory

Abstract: As an important foundation and key link in the construction of Guangdong-Hong Kong-Macao Greater Bay Area, port integration is facing multiple pressures such as internal industrial upgrading and international shipping competition. Building a matching supply chain and accelerating the upgrading of port industry are the keys to the construction of international shipping center and the exploration of free trade port. Based on the development status and future development trend of the ports in Guangdong-Hong Kong-Macao Greater Bay Area, this paper expounds the necessity and feasibility of the integration of the greater bay area Port in combination with game theory knowledge, and analyzes the key points and difficulties of port integration. Continuous development provides a reference for decision making, analyzes the key points and difficulties in the integration of the ports, so as to provide decision-making reference for the sustainable development of the ports.
\end{abstract}

\section{Introduction}

In recent years, under the background of vigorous development of marine economy, coastal provinces have shifted the focus of economic development from land to sea, taking ports as an important part of the development of marine economy. The regions involved in port integration in China include Hainan, Guangdong, Guangxi, Fujian, Zhejiang, Jiangsu, Hebei and Liaoning from south to north, while port integration involves not only the system, but also the game of interests of all parties, with numerous interest subjects, complex property rights structure and diverse capital composition. At present, China's port throughput increases year by year in terms of the world port throughput, but in the ranking of global port operators, China's "port group" is difficult to be listed [1]. As a result, problems such as "one bay, many ports", repeated construction of projects, internal competition and consumption have seriously restricted the economic transformation of port resource advantages and hindered the further sustainable development of port ecology. Therefore, the integration of port resources has become inevitable.

The Outline of the Development Plan for the Guangdong-Hong Kong-Macao Greater Bay Area has been announced to the public. It indicates that the construction of the greater bay area has entered a new historical stage of development. The port is a basic industry and an important link in the construction. It is a key part of the economic and social development, and also a strategy for developing the country's "One Belt and one Road", full play to the advantages of foreign trade. At present, the throughput of the port group in the Guangdong-Hong Kong-Macao Greater Bay Area has ranked the first in the world, which is called "super port group". However, most of the ports in the greater bay area (mainly Guangdong ports) are mainly Container-based; the port hinterland is becoming more and more assimilated. There is no clear division of labor and functional among major ports, and there is a lack of overall planning and coordination. Fierce vicious competition and serious repetitive construction result in weak overall competitiveness of ports and low utilization efficiency of shoreline resources [2]. Comparing with the Tokyo Bay Area, it is found that by 
coordinating and cooperating, the port groups can be classified into different levels and functions and become an organic group. Therefore, from the national strategic level, it is of great significance to actively promote the supply-side structural reform of the port industry and promote the sustainable development of port construction.

\section{Necessity and Feasibility of Port Integration in the Guangdong-Hong Kong-Macao Greater Bay Area}

After years of construction and development, the distribution pattern of the main coastal trade ports, such as Guangzhou Port, Shenzhen Port and Hong Kong Port, as well as the two major inland river ports, Foshan Port and Zhaoqing Port, has been formed in the Great Bay Area. The development trend of the ports facing the whole world has been gradually perfected, and the hinterland areas radiate from South China to Southwest China. It belongs to the most dense and busiest area in the world's ports. Since the "One Belt And One Road" initiative, the Great Bay Area has been actively responding to the national call. All the participants are committed to building a world-class port group as one of the main goals of the future greater bay area construction. The development of port group is about to embrace a new game pattern of competition and cooperation. Guangzhou, Shenzhen and Hong Kong are three important core port cities in the Great Bay Area of Guangdong, Hong Kong and Macao. Each of them has its own advantages in the development of port-vicinity industry and port specialization. In the new era, they are no longer limited to competition. They are more cooperative relations based on competition, and cooperation has become the mainstream of the development of port groups in the Great Bay Area. The key to cooperation lies in the complementary advantages of port resources and the construction of coordination mechanism [3]. The port integration of Guangdong, Hong Kong and Macao is not only in line with the national strategy, but also an important magic weapon to build a powerful port country and remain invincible in the competition of comprehensive port strength.

Therefore, the port integration of Guangdong, Hong Kong and Macao is of great significance for the formation of dislocation and coordinated development effect, complementary advantages, resource sharing, improvement of service quality and improvement of route efficiency. Facts have proved that the cooperative game between ports can help to improve industry concentration and resource allocation efficiency, avoid duplication of construction and homogeneous competition pattern. By adjusting the industrial structure of the ports, we have realized the differentiated and characteristic operation and optimized the resource allocation of the ports. Under the background of declining trade volume and declining prosperity of the ports in recent years, port integration will become a powerful tool for the supply side reform of the port industry in Guangdong, Hong Kong and Macao, and promote the sustainable development of the Great Bay Area.

\section{Key Points of Port Integration the Guangdong-Hong Kong-Macao Greater Bay Area}

Nowadays, the state has proposed the planning and construction of the Great Bay Area with Guangdong, Hong Kong and Macao as the main participants. The development of regional integration will inevitably lead to the integration of resources of the participants. And the port as the foundation of foreign trade bears the brunt of integration of the first pawn how to fall? The biggest breakthrough is the cooperation between port operation and management [6]. Existing game theory research results show that cooperation based on competition can not only reduce transaction costs by benign cluster effect, but also realize information sharing and effective supply of resources. However, the cluster effect cannot be brought into full play only through simple overlapping of ports, the repeated construction and disorderly competition among the participants will lead to the convergence of port function orientation and industrial structure, seriously inhibit the construction and play of the overall coordination effect of the port group in the Great Bay Area. 


\subsection{All-round and In-Depth Strategic Cooperation Between Guangdong, Hong Kong and Macao in the Great Bay Region}

Hong Kong is the leader of industry transfer and trade opening. Through gradual return to overseas investment, joint exchange and joint construction of maritime university, Hong Kong and Guangzhou Nansha Free Trade Zone have carried out in-depth cooperation in shipping service industry, led by Hong Kong with advantages in high-end value-added services such as trading, finance and pricing, strived for international shipping and the right to hold the International Shipping Forum, training high-end legal personnel for shipping arbitration, and promoting the upgrading of the Great Bay [4]. Guangzhou, Shenzhen and other ports in the Guangdong, Hong Kong and Macao Great Bay Area strive to create high-end services with their own characteristics and values while doing well in transportation and warehousing. They should not only be bigger but also stronger, adhere to strategic determination, embrace the development trend of the ind ustry and follow up for a long time.

\subsection{Construction of coordination mechanism among ports}

There are obvious differences among cities and ports in the Great Bay Area due to different levels of social and economic development. In addition, due to historical and institutional reasons, governments in the Great Bay Area often give more local development content to ports and bring administrative barriers between ports based on their own interests in Port Development planning, Further hindering the construction of complementary coordination mechanism between ports, seriously affecting the overall effectiveness of the play [5]. At present, with the introduction of the planning outline for the Great Bay Area of Guangdong, Hong Kong and Macao, the participants actively respond to the call of the state to plan the port integration work with a global awareness, promote the construction of logistics hub in the Great Bay Area, improve the efficiency of port resource allocation, and enhance the process of regional integration development and regional competitiveness. The construction of the port coordination mechanism in the Great Bay Area of Guangdong, Hong Kong and Macau is an important support for China's "one belt and one way" strategy. It needs not only the concerted efforts of the participants in the Great Bay Area, but also the determination to strengthen reform.

\section{Difficulties in the Integration of Ports in the Guangdong-Hong Kong-Macao Greater Bay Area}

As we all know, port integration is a game of interests. At present, there are the following difficulties in port integration in the Guangdong, Hong Kong, and Macao Great Bay Area:

\subsection{It is Difficult to Integrate Ports in the Guangdong-Hong Kong-Macao Greater Bay Area Due to the large difference in Investment subjects}

After the reform and opening-up, especially since the mid and late 1980s, China's economy has developed rapidly and steadily, and the rapid growth of foreign trade has led to the emergence of port construction. With the deepening of reform and opening-up, the main body of port investment has also shown diversified characteristics. In view of the historical development of Guangdong, Hong Kong and Macao and the differences in social systems in the Great Bay Area, the diversified characteristics of port investors are more prominent than those of other bay areas in the world and other regional ports in China. In the early stage of port development, different investors provided development funds and experience support for ports, at the same time; they also played an important role in stimulating and guiding the development of port groups. However, with the deepening of port construction and the convergence of economic hinterland, the competition between ports in Guangdong, Hong Kong and Macao Great Bay Area tends to be white-hot. Restricted by the differences of investment concept, management mode and development strategy, each port participant considers the maximization of local interests based on their own interests of individual rationality, which leads to the failure of the overall benefits of ports in the Great Bay 
Area, the absence of linkage and coordination among ports, and ultimately the formation of mutually restrictive development. The pattern severely restricts the overall level. If the port of Guangdong, Hong Kong, Macao can achieve the same unified planning and unified construction as the port of Zhejiang, there will be no competition problem. The port integration of Guangdong, Hong Kong and Macao involves the coordination of local government, provincial government and national level, which is beyond the provincial level to the national strategy.

\subsection{The difference in the system of port integration relationship between Guangdong, Hong} Kong and Macau is a change that that spans two social systems

Due to historical development, the integration of ports in the Greater Bay Area of Guangdong, Hong Kong and Macao is related to the coordination of two different social systems. This is also the difference between the port integration in the region and other ports in the world. In a region, two different social systems and three independent tariff systems have led to a serious division of ports in the Great Bay Area. To break down the inherent barriers, we must have a strong determination to reform. In the absence of any reference experience, the participants in the Guangdong, Hong Kong and Macao Great Bay Area should conform to the development direction of the times. Although the port integration of Guangdong, Hong Kong and Macao Great Bay Area under one country, two systems is quite different in terms of law and market. However, at the same time, it should emphasize the need for common ground while reserving differences, complement each other's strengths, coordinate development, and establish a clear coordination mechanism for the division of labor between ports to provide new impetus for the sustainable development of ports and hand in satisfactory answers. The key points and difficulties of port integration in Guangdong, Hong Kong and Macao are shown in Figure 1:

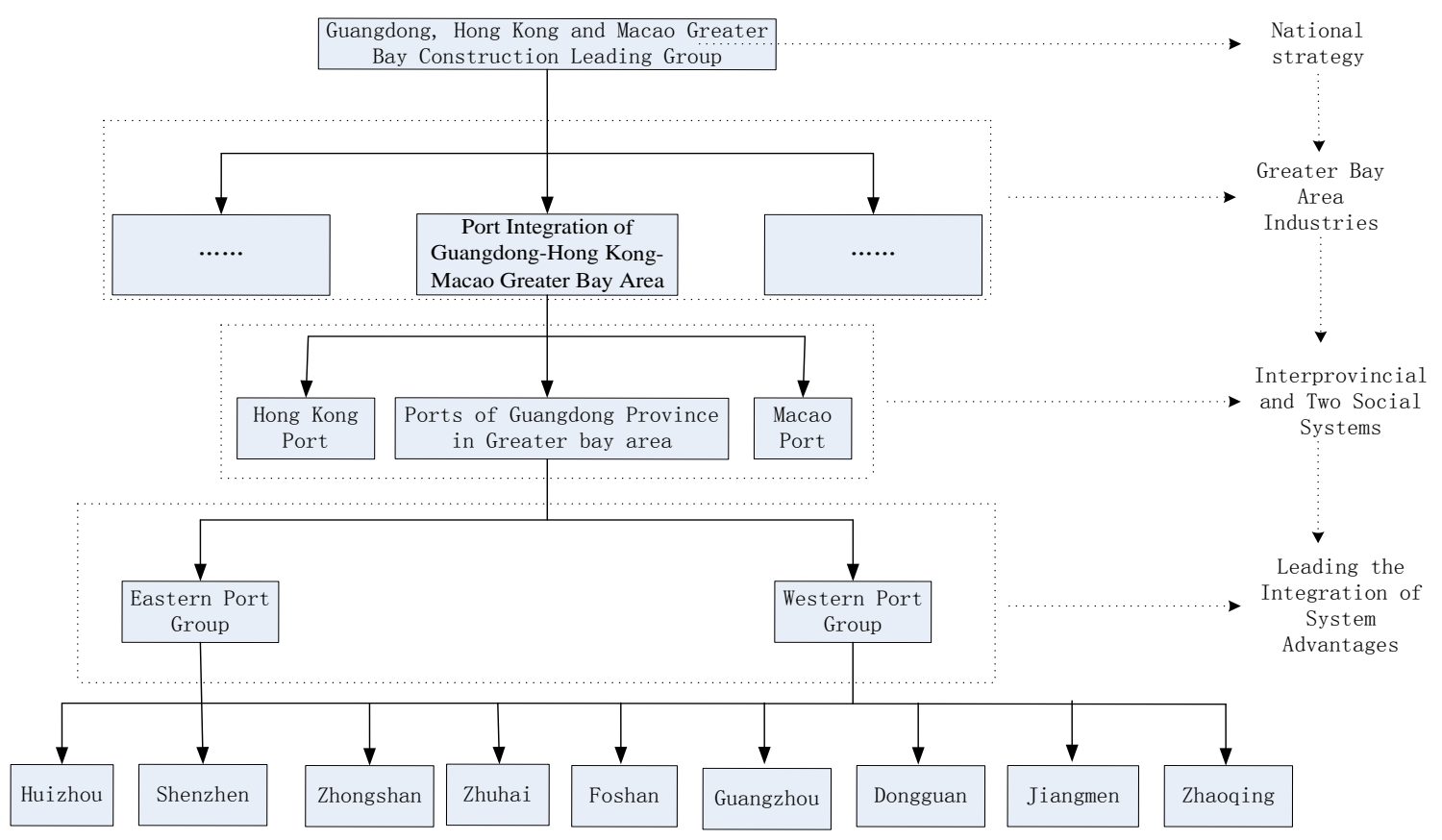

Fig.1 Port integration diagram of Guangdong-Hong Kong-Macao greater bay area.

\section{Summary}

The sustainable development of port integration in the Guangdong-Hong Kong-Macao Greater Bay Area should focus on Hong Kong Port, Shenzhen Port and Guangzhou Port, and take Dongguan Port, Zhuhai Port and other peripheral second-tier ports as replenishment. The coordination mechanism of dislocation development, cooperation and win-win situation should be implemented. The most possible way is to refer to the integration of supply chain. We can start from Guangdong, which has the advantages of system and mechanism. We should pay attention to the design of ownership structure. We should gradually transfer from administrative coordination to 
market coordination by holding shares. Oligopoly Port Group set up a port alliance, small groups to participate in the shares, through controlling rights to protect the right to speak in the port cooperation alliance, forming a community of interests, and thoroughly breaking the local protectionism in the Great Bay Area. At the same time, according to the characteristics of each participant, we should build the core competitiveness of the port, optimize the layout and positioning of the port function, make the long board longer and have better advantages, enhance the international competitiveness of the port group in Guangdong, Hong Kong and Macao, and actively advance to the port power.

\section{Acknowledgment}

The results are part of the project "Research on Port Integration and Promotion in Guangdong, Hong Kong and Macau Greater Bay Area: Based on the Perspective of Cooperation Game”, with grant number 2018GZGJ57, funded by Guangzhou Social Science Planning Leading Group Office.

\section{References}

[1] Xiao Y. The Emergence of Liaoning Port Unified Management Platform-the Rise of National Port Resource Integration. Review of Economic Research. 2017, 36:31-32.

[2] Shen Y, Ma Z.X. Constructing the New Pattern of Opening Policy Led by Bay Area Economy: An Empirical Analysis Based on the Degree of Opening in the Guangdong, HK\& Mac Bay Area. The Journal of Shanghai Administration Institute, 2017, 18(1): 83-91.

[3] Wang D.G. The development of ports under the background of the construction of the Guangdong-Hong Kong-Macao Greater Bay Area. China Ports, 2017, 12, 17-19.

[4] Chen M.M. Empirical Analysis of Port Group Positioning in the Guangdong-Hong Kong-Macau Big Bay Area. Journal of Shenzhen University (Humanities \& Social Sciences), 2016, 33(4): 32-35.

[5] Chen Y, Lin Z.H. Grey Correlation Analysis of Industrial Synergetic Development and Synergetic Mechanism Innovation in the Guangdong-Hong Kong-Macao greater bay area. Journal of Guangdong University of Finance \& Economics, 2018, (4): 89-97.

[6] Sun H. Research on the Function Optimization of Port Groups in the Pearl River Delta Region of China. DaLian Matitime University, 2015. 